\title{
Inhibition of tropomyosine receptor kinase B on the migration of human Schwann cell and dispersion of oral tongue squamous cell carcinoma in vitro
}

Liliana Ein MD¹, Olena Bracho BS ${ }^{1}$, Christine Mei BS ${ }^{1}$, Jaimin Patel BS ${ }^{1}$, Thomas Boyle $\mathrm{BS}^{1}$, Paula Monje $\mathrm{PhD}^{2}$, Cristina Fernandez-Valle $\mathrm{PhD}^{3}$, Esperanza Bas $\mathrm{PhD}^{1}$, Giovana Thomas MD¹, Donald Weed MD¹, Zoukaa Sargi MD MPH¹, Christine Dinh MD¹.

1. Department of Otolaryngology, University of Miami Miller School of Medicine, Miami, Florida.

2. Department of Neurological Surgery, Indiana University School of Medicine, Indianapolis, Indiana.

3. Burnett School of Biomedical Sciences, University of Central Florida College of Medicine, Orlando, Florida.

This is the author's manuscript of the article published in final edited form as:

Ein, L., Bracho, O., Mei, C., Patel, J., Boyle, T., Monje, P., ... \& Sargi, Z. (2019). Inhibition of tropomyosine receptor kinase $B$ on the migration of human Schwann cell and dispersion of oral tongue squamous cell carcinoma in vitro. Head \& neck, 41(12), 4069-4075. https://doi.org/10.1002/hed.25956 


\section{ABSTRACT}

\section{BACKGROUND}

Schwann cells (SC) may play an important role in perineural invasion (PNI) by promoting cancer cell dispersion. Brain-derived neurotrophic factor (BDNF) may contribute to these cellular events by activating tropomyosine receptor kinase $B(T r k B)$. This study examines the effect of TrkB inhibition on SC migration and oral cancer cell dispersion in vitro.

\section{METHODS}

Human tongue squamous cell carcinoma (SCC-9) and human SCs were cocultured in three different conditioned mediums: control, BDNF, and TrkB inhibitor. Cell migration, cancer cell dispersion, and SC dedifferentiation were measured on time-lapse and immunofluorescence images.

\section{RESULTS}

Cancer cell migration exceeded SC migration in all conditions. TrkB inhibition promoted SC dedifferentiation and significantly increased SC migration, when compared to BDNF conditions. TrkB inhibition also reduced cancer cell dispersion, when compared to control and BDNF-treated cultures.

\section{CONCLUSION}

SCs may have importance in the pathophysiology of PNI. TrkB inhibition may be a potential avenue for therapeutic intervention. 


\section{INTRODUCTION}

Head and neck cancers (HNC) account for $3 \%$ of all new diagnosis of cancers and $1.8 \%$ of all deaths related to cancer in the United States. Up to $95 \%$ of all HNC diagnosed are squamous cell carcinoma (SCC).1 A significant prognostic factor of HNC is perineural invasion (PNI). In head and neck squamous cell carcinoma (HNSCC), PNI is associated with a decreased rate of overall survival ( $23 \%$ with $\mathrm{PNI}$ vs $49 \%$ without $\mathrm{PNI}$ ), increased rate of local recurrence ( $23 \%$ with PNI vs $9 \%$ without $\mathrm{PNI}$ ), and increased disease-specific mortality ( $54 \%$ with $\mathrm{PNI}$ vs $25 \%$ without $\mathrm{PNI}) .2$, 3 This pathological feature is seen in up to $80 \%$ of cases. 4 The conventional route of metastasis, including lymphotropic and vasculotrophic, are well understood biochemically. 5 However, the molecular mechanisms of $\mathrm{PNI}$ remain an enigma.

PNI occurs when tumor invades around, along, and throughout different layers of named and unnamed nerves.6 In the classical theory of PNI, cancer was thought to invade nerves via the path of least resistance in the perineural space. However, the nerve sheath is actually composed of multiple layers of collagen and basement membrane, which makes this path highly resistant. PNI is likely due to more complex mechanisms of invasion rather than simple diffusion of cancer cells.7 According to newer theories, PNI involves reciprocal signaling interactions between tumor cells and nerves, where nerves release trophic factors that stimulate cancer cells and cancer cells release neurotrophic factors that stimulate nerve infiltration. HNSCC has been shown to secrete factors that lead to neurite outgrowth, including nerve growth factor (NGF), brain derived growth factor (BDNF), and neurotrophin-3 (NT-3). The interactions of these neurotrophins with their high affinity receptors, tropomyosine receptor kinase (Trk) A, TrkB, and TrkC, respectively, is a new area of interest in the development of pharmaceutical therapies for many types of cancers.8 In particular, the BDNF/TrkB pathway is overexpressed in HNSCCs and found to be associated with aggressive behavior, poor prognosis, and resistance to chemotherapy.

Schwann cells (SC) have been found to be closely associated with cancer cells in PNI specimens in colon cancer, thyroid cancer, salivary duct carcinomas, and skin squamous cell carcinomas.9-11 There is increasing evidence that SC play a major role in the tumor 
microenvironment, secreting neurotrophic factors and expressing high levels of Trk receptors.8, 12-16 Furthermore, cocultures of SC with salivary adenoid cystic carcinoma cells found increased BDNF secretion and TrkB expression, leading to epithelial-tomesenchymal transition (EMT) and mediation of the PNI process.17 Studies demonstrate that SC exhibit early and targeted migration toward human pancreatic cancer cells, preceding any cancer cell migration toward neurons in three-dimensional in vitro experiments.10 Deborde et al9 elucidated that dedifferentiated SC direct pancreatic cancer cell migration toward nerve in a neural cell adhesion molecule 1 (NCAM-1)dependent mechanism, leading to cancer invasion following direct cancer cell contact.9 These studies suggest that SC are activated in response to cancer cells, leading to a SCcancer cell interaction that induces cancer cell propagation and is worthy of further investigation.

The focus of this experiment was to analyze the communication between SC and cancer through BDNF activation of TrkB-receptor and how this may contribute to the cellular events in HNSCC. A novel TrkB inhibitor, ANA-12, was used to study the potential effects of downregulating the BDNF pathway and the in vitro implications for PNI (Figure 1).

\section{Figure 1.}

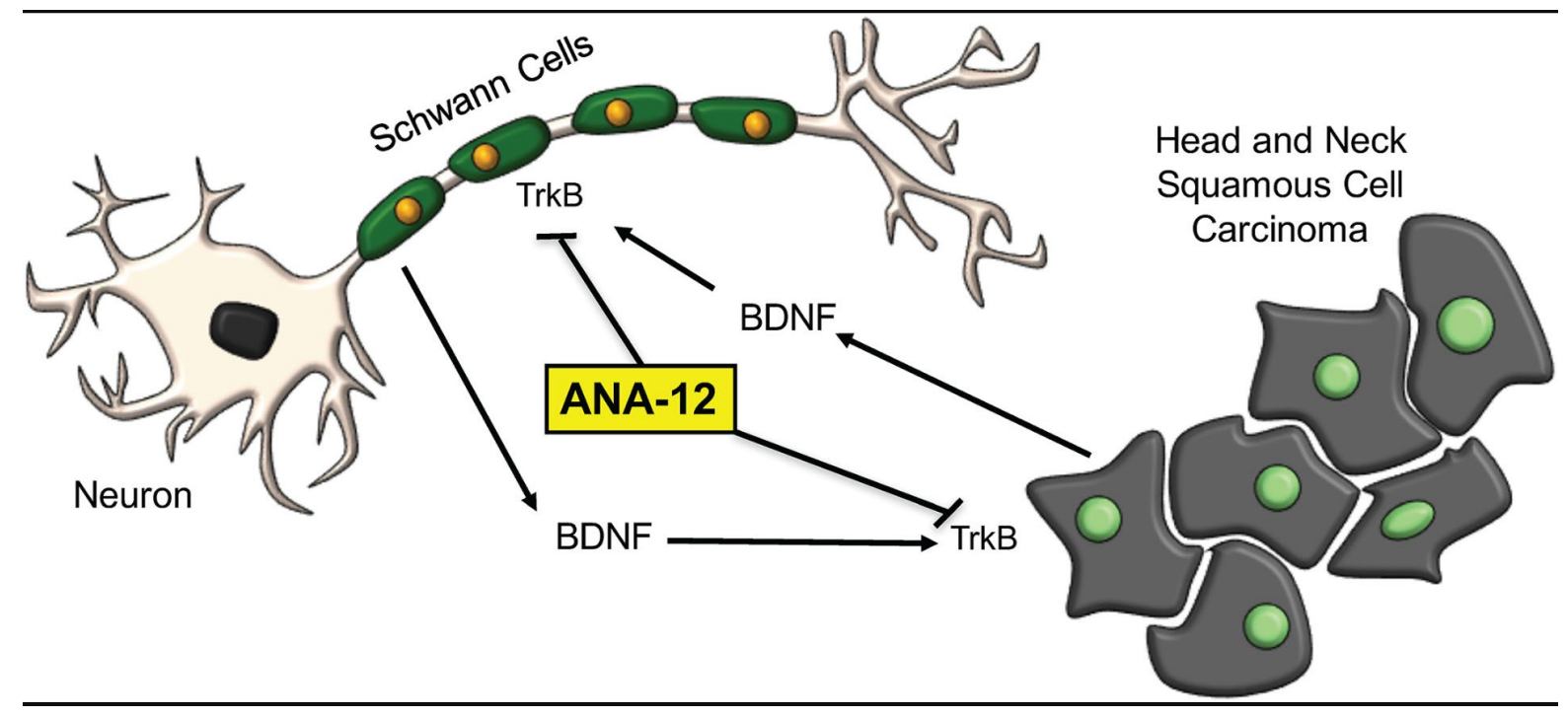

Communication between cancer and Schwann cells. An illustrative diagram demonstrating a potential mechanism of communication between head and neck 
squamous cell carcinoma and Schwann cells. Both cell types secrete brain-derived neurotrophic factor (BDNF) that activate tropomyosin kinase B (TrkB) receptor. ANA-12 is a drug that can potentially block communications between cell types through inhibition of the TrkB receptor.

\section{MATERIALS AND METHODS}

\subsection{CELL LINES AND CULTURE}

Primary human tongue squamous cell carcinoma (SCC9; CRL-1629) cell line was purchased from the American Type Culture Collection (ATCC) and cultured according to the manufacturer's protocol. In brief, these cancer cells were cultured in uncoated flasks with maintenance media, consisting of $10 \%$ heat inactivated fetal bovine serum (FBS, Seradigm) and 90\% mixture of Dulbecco's modified Eagle's medium (DMEM) and Ham's F12 medium (1:1) containing $1.2 \mathrm{~g} / \mathrm{L}$ sodium bicarbonate, $2.5 \mathrm{mM} \mathrm{L}$-glutamine, $15 \mathrm{mM}$ HEPES, $0.5 \mathrm{mM}$ sodium pyruvate, and $400 \mathrm{ng} / \mathrm{mL}$ hydrocortisone at $37^{\circ} \mathrm{C}, 5 \% \mathrm{CO}$. Primary human SC from normal peripheral nerve were obtained, purified, and cultured according to the methods reported by Monje.18 Briefly, the SC were plated on $0.01 \%$ poly-L-ornithine (Sigma Aldrich) and laminin $(5 \mu \mathrm{g} / \mathrm{mL}$; ThermoFisher) coated culture flasks in mitogenic media, consisting of DMEM (Sigma Aldrich), 10\% FBS (Seradigm), Forskolin (2 $\mu \mathrm{M}$; Sigma Aldrich), Heregulin (10 nM; Sigma Aldrich) and 1\% penicillinstreptomycin (Gibco). All cells were grown at $37^{\circ} \mathrm{C}$ in a $5 \% \mathrm{CO} 2$ incubator. Both cell lines were authenticated with immunofluorescence using primary antibodies against pancytokeratin (1:100, Novusbio, NBP2-29429, Littleton CO), involucrin (1:100, Abcam, SY5, ab68, Cambridge, MA), S100 (1:100, Abcam, Ab868, Cambridge, MA), and Glial fibrillary acidic protein (GFAP; 1:250, Dako, Z0334, Santa Clara, CA) (Figure S1).

For dispersion assays, three culture conditions were utilized and consist of DMEM, 5\% FBS, and $1 \%$ penicillin-streptomycin, supplemented with either: (a) vehicle $(0.05 \%$ dimethyl sulfoxide [DMSO], Sigma Aldrich), (b) $100 \mathrm{ng} / \mathrm{mL}$ BDNF recombinant human protein (ThermoFisher, \#10908010), or (c) 5 MM ANA-12 (Selleckchem, \#S7745) at $37^{\circ} \mathrm{C}$, $5 \% \mathrm{CO} 2$.

\subsection{VIABILITY ASSAY}


Cancer and SC were seeded in $0.01 \%$ poly-L-ornithine (Sigma Aldrich) and laminin (5 $\mu \mathrm{g} / \mathrm{mL}$ ) coated 96 -well black plates at 10000 cells/well and incubated for 96 hours in each of three conditioned media $(n=9-14)$. CellTiter-Glo viability assays (Promega, Fitchburg, WI) were conducted per manufacturer's protocol and relative luminescence units (RLU) were measured using a GloMax Discover luminometer (Promega, Fitchburg, WI). The culture conditions tested did not stimulate proliferation or initiate significant toxicity to cancer and $S C(P=.32$ and $P=.27$, respectively; Figure $S 2)$.

\subsection{WESTERN BLOT}

Western blots were performed to confirm expression of TrkB receptor and BDNF in both cancer and Schwann cell-lines (Figure S3). Protein was isolated using Mem-PER Plus Membrane Protein Extraction Kit (ThermoFisher, 89842, Waltham, MA). Protein concentration was measured using the BCA Protein Assay Kit (Pierce, Waltham, MA), per manufacturer's instruction. For western blotting, 25 to $100 \mu \mathrm{g}$ of proteins were loaded on a precast gel (MINI-protean TGX-Stain-Free Gel, Bio-Rad), separated by gel electrophoresis, and transferred to a nitrocellulose membrane. Membranes were blocked in $2.5 \% \mathrm{BSA}$ and incubated overnight in primary antibody solution at $4^{\circ} \mathrm{C}$ and Alexa Fluor 488 and 647-conjugated secondary antibodies (1:200, Life Technologies) for 2 hours at room temperature. The following primary antibodies were used: BDNF (1:500, Abcam, Ab78078, Cambridge, MA), TrkB (1:500, Abcam, Ab187041, Cambridge, MA), beta-actin (1:1000, Abcam, Ab8227, Cambridge, MA), and beta-tubulin (1:1000, ThermoFisher, 322600, Waltham, MA). Fluorescent images were obtained using the ImageQuant LAS 4000 Gel Biomolecular Imager (GE Healthcare Life Sciences). Monochromatic images demonstrated confirm expression of TrkB receptor and BDNF in both Schwann and cancer cells (Figure S3).

\subsection{MIGRATION AND DISPERSION ASSAY}

We created a migration and dispersion assay using 2-well insert dishes (Ibidi, 81 176, Fitchburg, WI), precoated with $0.01 \%$ poly-L-ornithine (Sigma Aldrich) and laminin (5- 10 $\mu \mathrm{g} / \mathrm{mL}$ ). Approximately 25000 cancer cells and SC were plated into each well for 24 hours 
in their respective culture media at $37^{\circ} \mathrm{C}, 5 \% \mathrm{CO} 2$ (Figure 2). After cells adhered to the dish, Qtracker (Thermo Fisher) was used to fluorescently label the cells per manufacturer's protocol. Cancer was labeled green (Qtracker 565, Q25031MP, Invitrogen, Eugene, OR) and SC were labeled pink (Qtracker 655, Q25021MP, Invitrogen, Eugene, OR). The inserts were removed, and the migration and dispersion assays were performed in three types of medias. Time lapse photos were taken daily for four days using a fluorescence microscope (Zeiss Axiovert 200 M, Germany). Day 0 photos were used to define the gap between cancer cells and SC. Cell migration was measured on days 0 -2. Cancer cell dispersion was quantified with images obtained on day 4 . This assay was replicated 9 to 14 times, depending on condition.

\section{Figure 2}
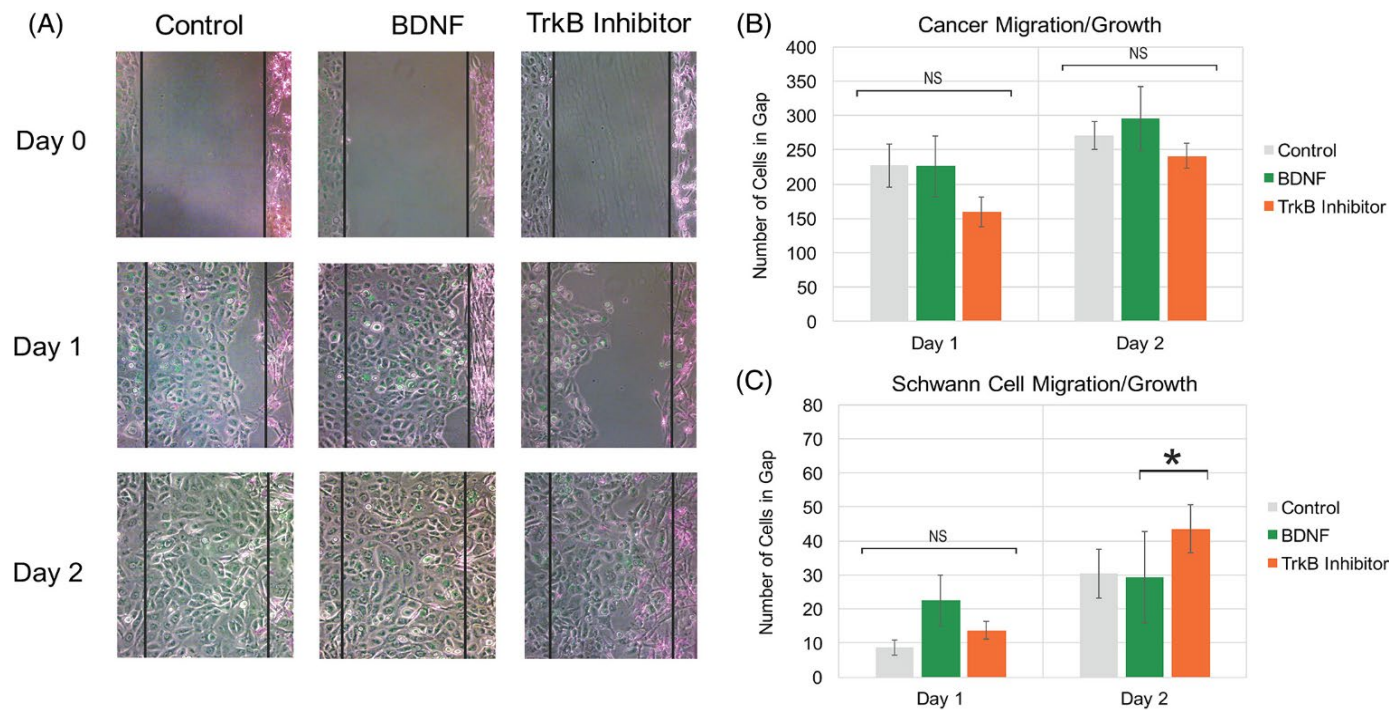

Migration assay. A, Representative images on days 0,1 , and 2 of cancer cells (green) and Schwann cells (pink) that have migrated into the gap following treatment with $0.05 \%$ DMSO (vehicle), $100 \mathrm{ng} / \mathrm{mL}$ BDNF, and $5 \mu \mathrm{M}$ ANA-12 (TrkB inhibitor). B and C, The average number of each cell type were measured within the gap on days 1 and 2 . There was no significant difference in cancer migration between all three conditions. However, there was significantly more SC migration on day 2 in the presence of TrkB inhibitor when compared to BDNF ( $P=.01$; Kruskal-Wallis and Wilcoxin rank sum tests). Bar represents 
mean. Error bars denote SE mean. ${ }^{*} \mathrm{P}<.05 . \mathrm{N}=9-14$ replicates per condition [Color figure can be viewed at wileyonlinelibrary.com]

\subsection{IMMUNOHISTOCHEMISTRY}

Approximately 10000 SC per well were plated onto 16-well chamber slides (Nunc LabTek, ThermoFisher, Waltham, MA) for 96 hours in the three conditioned medias. The slides were fixed with $4 \%$ paraformaldehyde, blocked, and permeabilized with $1 \%$ Triton X-100 (Sigma Aldrich), 5\% donkey serum (Sigma Alrich), in phosphate buffered saline (PBS, Sigma Aldrich). Subsequently, they were incubated with primary antibodies against GFAP overnight at $4^{\circ} \mathrm{C}$, followed by Alexa Fluor 488 and 633-conjugated secondary antibodies (Life Technologies, A11008, A21070,), and 4',6-diamidino-2-phenylindole (DAPI) nuclear stain. Antifade mounting medium was placed on slides prior to coverslipping. Images were obtained using a confocal microscope (Carl Zeiss LSM 700 Laser Scanning Confocal Microscope, Germany).

\subsection{STATISTICAL ANALYSIS}

Statistical analysis was performed with either: (a) analysis of variance test with TukeyKramer post-hoc tests for normally distributed data, or (b) two-sided Kruskal-Wallis test with Wilcoxon rank sum post-hoc tests for data without normal distribution. Significance was set at $\mathrm{P}<.05$.

\section{RESULTS}

\subsection{MIGRATION ASSAY}

Migration was measured by counting the number of cells of each cell type within the gap between cancer and SC. The size of the cell free gap was determined on day 0 after the well inserts were removed. By day 2, the gaps were completely filled with cells, which marked the end point for measuring migration. In all three conditions, there was more cancer migration into the gap than SC migration (Figure 2A). There was no difference in cancer migration across the three conditions $(P=.53$; Figure $2 B)$. Although there was no significant difference in $\mathrm{SC}$ migration on day 1 , differences were observed on day $2(\mathrm{P}=$ 
.04). On day 2, there was significantly more SC migration in the presence of TrkB inhibitor (ANA-12) when compared to BDNF conditions $(P=.01)$ (Figure $2 \mathrm{C})$.

\subsection{DISPERSION ASSAY}

For the dispersion assay, the average number of cancer cells dispersed by SC were measured on day 4. Representative images are shown in Figure 2A. In control and BDNF conditions, there was significant mixing of cells, with SC intercalating and encircling clusters of cancer cells. In contrast, there appeared to be a very well defined border between SC and cancer cells in the presence of TrkB inhibitor, ANA-12 (Figure 3A). SCassociated cancer cell dispersion was quantified by counting the number of cancer cells that were completely surrounded by SC. In the presence of TrkB inhibitor, there was significantly less cancer cell dispersion, when compared to BDNF and control groups ( $P$ $<.001$ and $\mathrm{P}<.001$, respectively). There was no significant difference between BDNF and control conditions $(P=.14$; Figure $3 \mathrm{~B})$.

Figure 3

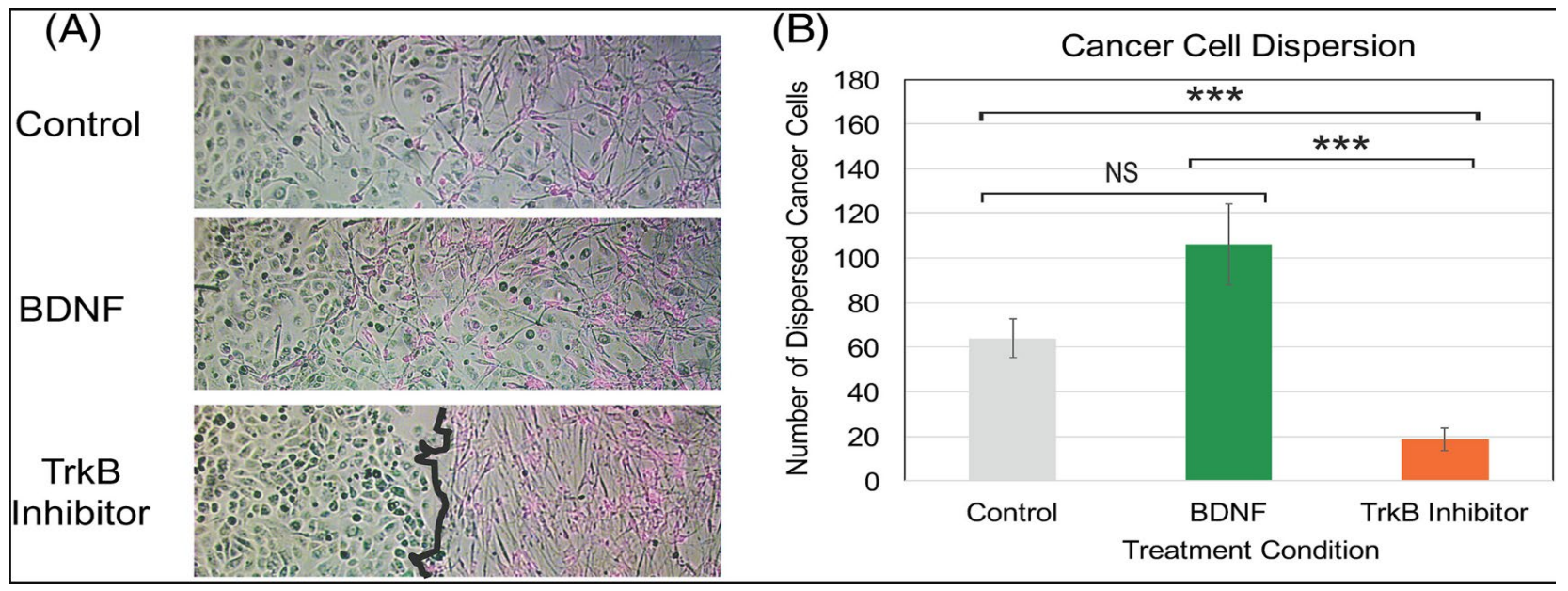

Dispersion assay. A, Representative images on day 4 at $6 \times$ magnification of cancer cells (green) and Schwann cells (pink) after treatment with $0.05 \%$ DMSO (control), $100 \mathrm{ng} / \mathrm{mL}$ BDNF, and $5 \mu \mathrm{M}$ ANA-12 (TrkB inhibitor). There was significantly more intercalation and mixing of cancer cells and Schwann cells at the border in control (DMSO) and BDNF conditions, whereas there is a well-defined border between cell types with TrkB inhibition (ANA-12). B, Cancer cell dispersion was measured by the number of cancer cells that 
were completely surrounded by Schwann cells. There was significantly less cancer cell dispersion with the addition of a TrkB inhibitor (ANA-12), when compared to both control (DMSO) and BDNF conditions $(P<.001$ and $P<.001$, respectively; Kruskal-Wallis and Wilcoxin rank sum tests). There was no significant difference between BDNF and control conditions. Bar represents mean. Error bars denote SE mean. $\mathrm{N}=11-14$ replicates per condition. NS, not significant. ${ }^{* * *} \mathrm{P}<.01$ [Color figure can be viewed at wileyonlinelibrary.com]

\subsection{IMMUNOFLUORESCENCE AND DEDIFFERENTIATION}

To determine whether SC have the propensity to dedifferentiate under certain conditions, immunofluorescence was performed on SC exposed to either control, BDNF, or TrkB inhibition (ANA-12) conditions. GFAP was used as a marker of a dedifferentiated and motile state. In control conditions, SC expressed an intermediate degree of GFAP. In the presence of BDNF, there was minimal GFAP staining, suggesting that BDNF may promote SC conversion into a more mature state. In contrast, when exposed to a TrkB inhibitor, there was intense GFAP expression, which suggests a more dedifferentiated and motile form (Figure 4).

Figure 4
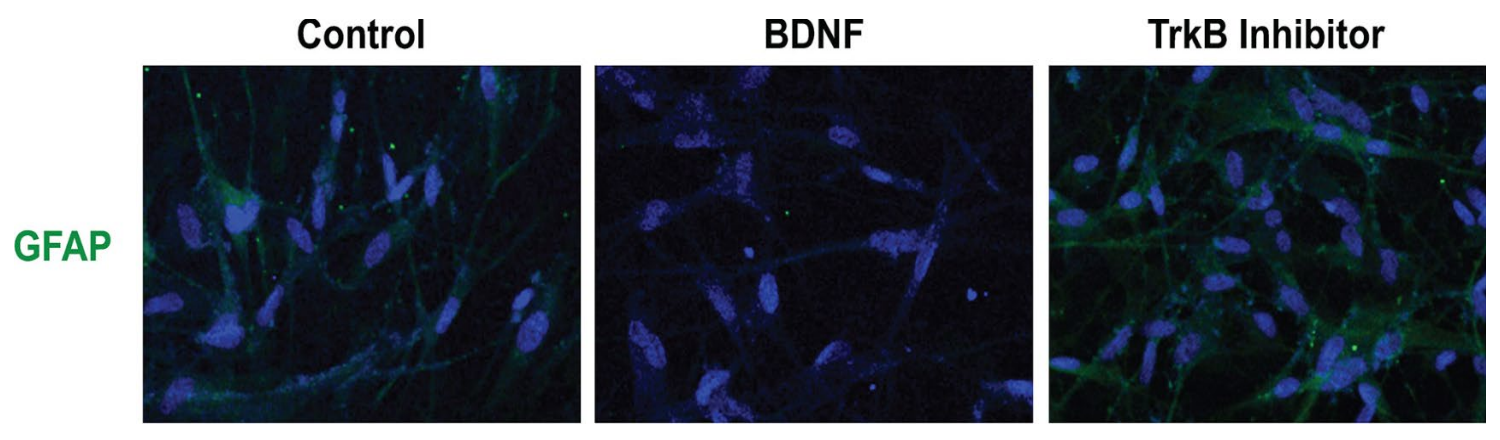

Immunofluorescence. To evaluate the effect of BDNF and TrkB inhibition on Schwann cell dedifferentiation, we cultured Schwann cells for 96 hours in $0.05 \%$ DMSO (control), $100 \mathrm{ng} / \mathrm{mL}$ BDNF, and $5 \mu \mathrm{M}$ ANA-12 (TrkB inhibitor). Immunofluorescence for GFAP (green), a marker of dedifferentiation, was performed. Images were taken at $20 x$ magnification. Nuclei were labeled with DAPI (blue). In control conditions, there is intermediate staining of GFAP. In the presence of BDNF, there is minimal GFAP 
expression, signifying a more quiescent state. In the presence of TrkB inhibitor (ANA-12), there is intense GFAP, signifying a more dedifferentiated state [Color figure can be viewed at wileyonlinelibrary.com]

\section{DISCUSSION}

Investigations into PNI can be dated as far back as 1963; however, the mechanisms of action remain clouded.19 While PNI in HNSCC is usually asymptomatic, advanced stage disease can be associated with significant morbidity as the cranial nerves become more grossly involved in the disease. Even microscopic PNI can have a negative impact on patient quality of life, as it is an indication to initiate adjuvant radiotherapy for head and neck cancer. Even so, prognosis is worse with PNI with regards to locoregional control.20

Understanding the interactions between cancer cells and the nerve microenvironment can lead to development of new therapeutic interventions for patients with PNI. Based on recent studies, SC and neurotrophic factors are important targets to explore and could have substantial implications for risk stratification and guidance of treatment. Recent studies have shown that SC properties that are used in nerve repair may also be activated in response to cancer. Dedifferentiated SC re-express proteins such as GFAP and NCAM during nerve repair. Deborde et al9 showed how SC that express NCAM can migrate toward pancreatic cancer cells, intercalate between cancer cell clusters, and direct cancer cell migration toward nerves.9 Our study shows similar findings in our in vitro model with SC dispersing cancer cells by extending their processes to intercalate and surround cancer cell clusters.

Demir et al 10 showed through a series of three-dimensional in vitro experiments that both human and rat SC exhibit early and targeted migration toward human pancreatic cancer cells well before the onset of pancreatic cancer cell migration toward neurons. This highly specific migration of GFAP-positive SC toward cancer cells was also seen in the presence of human colon cancer cells, but was not seen in response to benign human pancreatic and colon epithelial cells or benign glioblastoma cells. These findings suggested that SC are activated in response to cancer cells, and then migrate toward cancer before the onset of cancer migration toward nerves. Interestingly, when SC were pretreated with an inhibitor of TrkA, the high affinity receptor for NGF, both of which are 
highly expressed in pancreatic cancer, they found a decrease in Schwann cell migration toward pancreatic cancer. 10

Evidence has shown that neurotrophic receptor B (TrkB), a receptor tyrosine kinase, is an important regulator of oncogenesis and tumor progression in nerve tissue. Multiple studies have eluded to the involvement of TrkB in increasing migratory and invasion capacities of neurogenic tumor cell lines,21 promoting cancer cell survival,22 inhibiting chemotherapy-induced apoptosis of cancer,23 and developing metastasis in mouse models.24, 25 These findings suggest that TrkB and its ligand BDNF are critical components for cancer growth and progression, making it an avenue to study interventions for PNI.

In our study, we chose to evaluate the effect of BDNF and TrkB due to increasing number of reports showing elevated expression of these molecules and receptors in head and neck cancer.17, 26, 27 Our work is in line with recent studies that SC may play a role in promoting PNI. We demonstrate that when human tongue cancer and SC are grown in coculture, there is significant intercalation and mixing of both cell types (Figure 3). We can modulate these interactions by exogenous administration of BDNF or TrkB inhibitor. While there were high levels of cellular intermixing with BDNF treatment, TrkB inhibition with ANA-12 resulted in a well-defined border between cancer cells and SC. These findings suggest that TrkB inhibition may be altering the microenvironment in such a way that it is preventing the intercalation of $\mathrm{SC}$ and forming a barrier to cancer cell dispersion. Further investigations are warranted.

Our investigation also demonstrates that human SC and cancer cells express both BDNF and TrkB and exogenous administration of recombinant BDNF and TrkB inhibitor can modulate SC differentiation (Figure 4). When SC are treated with BDNF, they do not express GFAP, suggesting a more quiescent and myelinating state. When SC are exposed to TrkB inhibitor, they express intense GFAP staining, suggesting the cells have transformed into a more dedifferentiated and motile state. The association between SC dedifferentiation with TrkB inhibition and the prevention of cancer cell dispersion is not entirely clear; however, demonstrates a phenomenon that may be protective against cancer cell invasion. 
Although advantageous for studying mechanisms of action between individual cells types, the main limitation of two-dimensional in vitro models is that it does not replicate the threedimensional microenvironment that is better investigated using in vivo or even threedimensional in vitro models. In addition, while we are studying potential mechanisms of PNI, we chose not to include neurons in this pilot study to avoid confounding factors at this early level of investigation. While HNSCC is known to invade nerves, there are other cell lines in the head and neck that are more prone to PNI, such as adenoid cystic carcinoma. Studying these cells lines may give more clues toward mechanisms of PNI; however, there is controversy whether available cell lines are representative of adenoid cystic carcinoma and therefore they were not utilized. Furthermore, there are many factors that can potentially influence PNI, including other neutrophins, chemokines, and extracellular matrix components. This study focuses on the impact of the BDNF-TrkB axis on SC migration and dispersion of HNSCC. Future directions should include multiple cancer and SC lines and in vitro models of PNI, including use of neuronal and dorsal root ganglion cultures. Moreover, TrkB inhibition in animal models of PNI should be explored.

\section{CONCLUSION}

In addition to HNSCC, $\mathrm{PNI}$ is found in a number of different cancers, such as pancreas, colon, rectum, gastric, prostate, and biliary tract. Understanding the role of SC and neurotrophic factors in the pathophysiology of PNI may have important implications for therapeutic intervention. The need to identify the exact mechanisms of PNI is evident and further studies are warranted.

\section{AUTHOR CONTRIBUTIONS}

All authors were involved in the design, conduct, and/or analysis of research as well as the preparation and review of the manuscript. 


\section{REFERENCES}

1. SEER Cancer Stat Facts: Oral Cavity and Pharynx Cancer. Bethesda, MD: National Cancer Institute, 2019. http://seer.cancer.gov/statfacts/html/oralcav.html.

2. Fagan, J. J., Collins, B., Barnes, L., D’Amico, F., Myers, E. N., \& Johnson, J. T. (1998). Perineural Invasion in Squamous Cell Carcinoma of the Head and Neck. Archives of Otolaryngology-Head \& Neck Surgery, 124(6), 637-640. https://doi.org/10.1001/archotol.124.6.637

3. Soo, K.-C., Carter, R. L., O’Brien, C. J., Barr, L., Bliss, J. M., \& Shaw, H. J. (1986). Prognostic implications of perineural spread in squamous carcinomas of the head and neck. The Laryngoscope, 96(10), 1145-1148. https://doi.org/10.1288/00005537198610000-00015

4. Soo, K.-C., Carter, R. L., O’Brien, C. J., Barr, L., Bliss, J. M., \& Shaw, H. J. (1986). Prognostic implications of perineural spread in squamous carcinomas of the head and neck. The Laryngoscope, 96(10), 1145-1148. https://doi.org/10.1288/00005537198610000-00015

5. Allen, C. T., Law, J. H., Dunn, G. P., \& Uppaluri, R. (2013). Emerging insights into head and neck cancer metastasis. Head \& Neck, 35(11), 1669-1678. https://doi.org/10.1002/hed.23202

6. Liebig, C., Ayala, G., Wilks, J. A., Berger, D. H., \& Albo, D. (2009). Perineural invasion in cancer. Cancer, 115(15), 3379-3391. https://doi.org/10.1002/cncr.24396

7. Amit, M., Na'ara, S., \& Gil, Z. (2016). Mechanisms of cancer dissemination along nerves. Nature Reviews Cancer, 16(6), 399-408. https://doi.org/10.1038/nrc.2016.38

8. Roh, J., Muelleman, T., Tawfik, O., \& Thomas, S. M. (2015). Perineural growth in head and neck squamous cell carcinoma: A review. Oral Oncology, 51(1), 16-23. https://doi.org/10.1016/j.oraloncology.2014.10.004

9. Deborde, S., Omelchenko, T., Lyubchik, A., Zhou, Y., He, S., McNamara, W. F., Chernichenko, N., Lee, S.-Y., Barajas, F., Chen, C.-H., Bakst, R. L., Vakiani, E., He, S., Hall, A., \& Wong, R. J. (2016). Schwann cells induce cancer cell dispersion and invasion. The Journal of Clinical Investigation, 126(4), 1538-1554. https://doi.org/10.1172/JCl82658 
10. Demir, I. E., Boldis, A., Pfitzinger, P. L., Teller, S., Brunner, E., Klose, N., Kehl, T., Maak, M., Lesina, M., Laschinger, M., Janssen, K.-P., Algül, H., Friess, H., \& Ceyhan, G. O. (2014). Investigation of Schwann Cells at Neoplastic Cell Sites Before the Onset of Cancer Invasion. JNCl: Journal of the National Cancer Institute, 106(8). https://doi.org/10.1093/jnci/dju184

11. Deborde, S., \& Wong, R. J. (2017). How Schwann cells facilitate cancer progression in nerves. Cellular and Molecular Life Sciences, 74(24), 4405-4420. https://doi.org/10.1007/s00018-017-2578-x

12. Yilmaz, T., Jiffar, T., Garza, G. de la, Lin, H., Maclntyre, T., Brown, J. L., Myers, J. N., \& Kupferman, M. E. (2010). Therapeutic targeting of Trk supresses tumor proliferation and enhances cisplatin activity in HNSCC. Cancer Biology \& Therapy, 10(6), 644-653. https://doi.org/10.4161/cbt.10.6.12782

13. Ketterer, K., Rao, S., Friess, H., Weiss, J., Büchler, M. W., \& Korc, M. (2003). Reverse Transcription-PCR Analysis of Laser-Captured Cells Points to Potential Paracrine and Autocrine Actions of Neurotrophins in Pancreatic Cancer. Clinical Cancer Research, 9(14), 5127-5136.

14. Kowalski, P. J., \& Paulino, A. F. G. (2002). Perineural invasion in adenoid cystic carcinoma: Its causation/promotion by brain-derived neurotrophic factor. Human Pathology, 33(9), 933-936. https://doi.org/10.1053/hupa.2002.128249

15. Miknyoczki, S. J., Lang, D., Huang, L., Klein-Szanto, A. J. P., Dionne, C. A., \& Ruggeri, B. A. (1999). Neurotrophins and Trk receptors in human pancreatic ductal adenocarcinoma: Expression patterns and effects on In vitro invasive behavior. International Journal of Cancer, 81(3), 417-427. https://doi.org/10.1002/(SICl)10970215(19990505)81:3<417::AID-IJC16>3.0.CO;2-6

16. Okugawa, Y., Tanaka, K., Inoue, Y., Kawamura, M., Kawamoto, A., Hiro, J., Saigusa, S., Toiyama, Y., Ohi, M., Uchida, K., Mohri, Y., \& Kusunoki, M. (2013). Brain-derived neurotrophic factor/tropomyosin-related kinase B pathway in gastric cancer. British Journal of Cancer, 108(1), 121-130. https://doi.org/10.1038/bjc.2012.499

17. Kupferman, M. E., Jiffar, T., El-Naggar, A., Yilmaz, T., Zhou, G., Xie, T., Feng, L., Wang, J., Holsinger, F. C., Yu, D., \& Myers, J. N. (2010). TrkB induces EMT and has a key role 
in invasion of head and neck squamous cell carcinoma. Oncogene, 29(14), 2047-2059. https://doi.org/10.1038/onc.2009.486

18. Monje, P. V. (2018). Scalable Differentiation and Dedifferentiation Assays Using NeuronFree Schwann Cell Cultures. In P. V. Monje \& H. A. Kim (Eds.), Schwann Cells: Methods and Protocols (pp. 213-232). Springer. https://doi.org/10.1007/978-1-4939-7649-2 14

19. Ballantyne, A. J., McCarten, A. B., \& Ibanez, M. L. (1963). The extension of cancer of the head and neck through peripheral nerves. The American Journal of Surgery, 106(4), 651667. https://doi.org/10.1016/0002-9610(63)90074-6

20. Frunza, A., Slavescu, D., \& Lascar, I. (2014). Perineural invasion in head and neck cancers-A review-. Journal of Medicine and Life, 7(2), 121-123.

21. Matsumoto, K., Wada, R. K., Yamashiro, J. M., Kaplan, D. R., \& Thiele, C. J. (1995). Expression of Brain-derived Neurotrophic Factor and p145TrkB Affects Survival, Differentiation, and Invasiveness of Human Neuroblastoma Cells. Cancer Research, 55(8), 1798-1806.

22.Pearse, R. N., Swendeman, S. L., Li, Y., Rafii, D., \& Hempstead, B. L. (2005). A neurotrophin axis in myeloma: TrkB and BDNF promote tumor-cell survival. Blood, 105(11), 4429-4436. https://doi.org/10.1182/blood-2004-08-3096

23. Jaboin, J., Kim, C. J., Kaplan, D. R., \& Thiele, C. J. (2002). Brain-derived Neurotrophic Factor Activation of TrkB Protects Neuroblastoma Cells from Chemotherapy-induced Apoptosis via Phosphatidylinositol 3'-Kinase Pathway. Cancer Research, 62(22), 67566763.

24.Douma, S., van Laar, T., Zevenhoven, J., Meuwissen, R., van Garderen, E., \& Peeper, D. S. (2004). Suppression of anoikis and induction of metastasis by the neurotrophic receptor TrkB. Nature, 430(7003), 1034-1039. https://doi.org/10.1038/nature02765

25. Geiger, T. R., \& Peeper, D. S. (2007). Critical Role for TrkB Kinase Function in Anoikis Suppression, Tumorigenesis, and Metastasis. Cancer Research, 67(13), 6221-6229. https://doi.org/10.1158/0008-5472.CAN-07-0121

26. Zhu, L., Werner, J. A., \& Mandic, R. (2007). Implications of Tropomyosin-related Kinase B (TrkB) in Head and Neck Cancer. Anticancer Research, 27(5A), 3121-3126.

27. Dudás, J., Bitsche, M., Schartinger, V., Falkeis, C., Sprinzl, G. M., \& Riechelmann, H. (2011). Fibroblasts produce brain-derived neurotrophic factor and induce mesenchymal 
transition of oral tumor cells. Oral Oncology, 47(2), 98-103. https://doi.org/10.1016/j.oraloncology.2010.11.002 